\title{
Design Thermal Comfort in Greenhouses Environment
}

\author{
Abdeen Mustafa Omer* \\ Energy Research Institute (ERI), Forest Road West, Nottingham NG7 4EU, UK
}

\begin{abstract}
The move towards a de-carbonised world, driven partly by climate science and partly by the business opportunities it offers, will need the promotion of environmentally friendly alternatives, if an acceptable stabilisation level of atmospheric carbon dioxide is to be achieved. This requires the harnessing and use of natural resources that produce no air pollution or greenhouse gases and provides comfortable coexistence of human, livestock, and plants. This study reviews the energy-using technologies based on natural resources, which are available to and applicable in the farming industry. Among these are greenhouses, which are necessary for the growth of some plants (i.e., vegetables, flowers, etc.) in severe climates. However, greenhouses require some air conditioning process to control their temperature and relative humidity to suit specific plants. To achieve this, a novel air humidifier and/or dehumidifier systems using mop fans had been designed and employed in an experimental greenhouse to evaluate its performance under a controlled environment. This device helped to reduce the energy consumption of the greenhouse whilst providing a pleasant environment for the plants inside the greenhouse. The system was designed taking into account the meteorological conditions, which affect the environment inside the greenhouse. The performance of the system was monitored over a period of time by measuring the temperature and relative humidity of the greenhouse. Results of the monitoring have shown that the system was able to provide comfortable conditions (temperatures of 16$26 \mathrm{oC}$ and relative humidity of $65 \%$ ) suitable for the plants grown in the experimental greenhouse. It also enabled the minimisation of temperature variation and, hence, avoided the hazard of any sudden climatic change inside the greenhouse.
\end{abstract}

Keywords: Greenhouse environment, Energy efficient comfort, Ventilation,Humidity, Sustainable environmental impact

\section{Introduction}

Globally, buildings are responsible for approximately $40 \%$ of the total world annual energy consumption. ${ }^{1}$ Most of this energy is for the provision of lighting, heating, cooling, and air conditioning. Increasing awareness of the environmental impact of $\mathrm{CO}_{2}$ and $\mathrm{NO}_{\mathrm{x}}$ emissions and CFCs triggered a renewed interest in environmentally friendly cooling, and heating technologies. Under the 1997 Montreal Protocol, governments agreed to phase out chemicals used as refrigerants that have the potential to destroy stratospheric ozone. It was therefore considered desirable to reduce energy consumption and decrease the rate of depletion of world energy reserves and pollution of the environment.

One way of reducing building energy consumption is to design building, which is more economical in their use of energy for heating, lighting, cooling, ventilation and hot water supply. Passive mea sures, particularly natural or hybrid ventilation rather than air-conditioning, can dramatically reduce primary energy consumption. ${ }^{2}$ However, exploitation of renewable energy in buildings and agricultural greenhouses can, also, significantly contribute towards reducing dependency on fossil fuels. Therefore, promoting innovative renewable applications and reinforcing the renewable energy market will contribute to preservation of the ecosystem by reducing emissions at local and global levels. This will also contribute to the amelioration of environmental conditions by replacing conventional fuels with renewable energies that produce no air pollution or greenhouse gases.

The provision of good indoor environmental quality while achieving energy and cost efficient operation of the heating, ventilating and air-conditioning (HVAC) plants in buildings represents a multi variant problem. The comfort of building occupants is de-

\begin{tabular}{l|l}
\hline Quick Response Code: & FCorresponding author: Abdeen Mustafa Omer, Energy Research Institute (ERI), Forest Road \\
West, Nottingham NG7 4EU, UK \\
Received: 04 May, $2021 \quad$ Published: 18 May, 2021 \\
Citation: Abdeen Mustafa Omer. Design Thermal Comfort in Greenhouses Environment. Mod \\
Tech Agri Horti Sci. 2021;1(1):1-7. D0I: 10.53902/MTAHS.2021.01.000501
\end{tabular}


pendent on many environmental parameters including air speed, temperature, relative humidity and quality in addition to lighting and noise. The overall objective is to provide a high level of building performance (BP), which can be defined as indoor environmental quality (IEQ), energy efficiency (EE) and cost efficiency (CE).

a. Indoor environmental quality is the perceived condition of comfort that building occupants experience due to the physical and psychological conditions to which they are exposed by their surroundings. The main physical parameters affecting IEQ are air speed, temperature, relative humidity and quality.

b. Energy efficiency is related to the provision of the desired environmental conditions while consuming the minimal quantity of energy.

c. Cost efficiency is the financial expenditure on energy relative to the level of environmental comfort and productivity that the building occupants attained. The overall cost efficiency can be improved by improving the indoor environmental quality and the energy efficiency of a building.

An approach is needed to integrate renewable energies in a way to meet high building performance. However, because renewable energy sources are stochastic and geographically diffuse, their ability to match demand is determined by adoption of one of the following two approaches ${ }^{2}$ : the utilisation of a capture area greater than that occupied by the community to be supplied, or the reduction of the community's energy demands to a level commensurate with the locally available renewable resources.

For a northern European climate, which is characterised by an average annual solar irradiance of $150 \mathrm{Wm}^{-2}$, the mean power production from a photovoltaic component of $13 \%$ conversion efficiency is approximately $20 \mathrm{Wm}^{-2}$. For an average wind speed of $5 \mathrm{~ms}^{-1}$, the power produced by a micro wind turbine will be of a similar order of magnitude, though with a different profile shape. In the UK, for example, a typical office building will have a demand in the order of $300 \mathrm{kWhm}^{-2} \mathrm{yr}^{-1}$. This translates into approximately $50 \mathrm{Wm}^{-2}$ of façade, which is twice as much as the available renewable energies. ${ }^{3}$ Thus, the aim is to utilise energy efficiency measures in order to reduce the overall energy consumption and adjust the demand profiles to be met by renewable energies. For instance, this approach can be applied to greenhouses, which use solar energy to provide indoor environmental quality. The greenhouse effect is one result of the differing properties of heat radiation when it is generated at different temperatures. Objects inside the greenhouse, or any other building, such as plants, re-radiate the heat or absorb it. Because the objects inside the greenhouse are at a lower temperature than the sun, the re-radiated heat is of longer wavelengths, and cannot penetrate the glass. This re-radiated heat is trapped and causes the temperature inside the greenhouse to rise. Note that the atmosphere surrounding the earth, also, behaves as a large greenhouse around the world. Changes to the gases in the atmosphere, such as increased carbon dioxide content from the burning of fossil fuels, can act like a layer of glass and reduce the quantity of heat that the planet earth would otherwise radiate back into space. This particu- lar greenhouse effect, therefore, contributes to global warming. The application of greenhouses for plants growth can be considered one of the measures in the success of solving this problem. Maximising the efficiency gained from a greenhouse can be achieved using various approaches, employing different techniques that could be applied at the design, construction and operational stages. The development of greenhouses could be a solution to farming industry and food security.

The move towards a de-carbonised world, driven partly by climate science and partly by the business opportunities it offers, will need the promotion of environmentally friendly alternatives, if an acceptable stabilisation level of atmospheric carbon dioxide is to be achieved. This requires the harnessing and use of natural resources that produce no air pollution or greenhouse gases and provides comfortable coexistence of human, livestock, and plants. This study reviews the energy-using technologies based on natural resources, which are available to and applicable in the farming industry. Integral concept for buildings with both excellent indoor environment control and sustainable environmental impact are reported in the present communication. Techniques considered are hybrid (controlled natural and mechanical) ventilation including night ventilation, thermo-active building mass systems with free cooling in a cooling tower, and air intake via ground heat exchangers. Special emphasis is put on ventilation concepts utilising ambient energy from air ground and other renewable energy sources, and on the interaction with heating and cooling. It has been observed that for both residential and office buildings, the electricity demand of ventilation systems is related to the overall demand of the building and the potential of photovoltaic systems and advanced co-generation units. The focus of the world's attention on environmental issues in recent years has stimulated response in many countries, which have led to a closer examination of energy conservation strategies for conventional fossil fuels. One way of reducing building energy consumption is to design buildings, which are more economical in their use of energy for heating, lighting, cooling, ventilation and hot water supply. Passive measures, particularly natural or hybrid ventilation rather than air-conditioning, can dramatically reduce primary energy consumption. However, exploitation of renewable energy in buildings and agricultural greenhouses can, also, significantly contribute towards reducing dependency on fossil fuels. The main advantages of solar greenhouse are summarised as follows:

a. In the climatic conditions of Europe, the collector system equipped with linear raster lenses is able to absorb, on average, $12 \%$ of the total incoming global solar energy on the collector and convert this energy into heat at a temperature of between 30 to $50^{\circ} \mathrm{C}$. The system, therefore, consumes approximately $50 \%$ less energy for heating purposes than would a traditional normal greenhouse.

b. The system provides suitable, perhaps ideal, conditions for the cultivation of high quality vegetables, and even during periods of maximum solar energy absorption on the collectors, there still remains sufficient light for good vegetable growth under the area of the collectors. 
c. Due to the almost continuous high humidity levels and to the applied nutrient solution being rich in organic matter and microorganisms, organic matter is hardly mineralising in the soil, hence, does not degrade in patches. On the contrary, organic matter content in the soil increased during cultivation.

d. In comparison with a traditional greenhouse, the system does not overheat inside. Therefore, less ventilation is necessary, which brings the benefits of smaller losses of water. Furthermore, the system saves energy, allows the efficient recycling of water and nutrients, and provides suitable growth conditions with a smaller range of extreme humidity, temperature and light allowing the cultivated plants to face less stress and have a higher quality.

e. Due to the relatively low temperature in the greenhouse, additional heating might be required. Therefore, vegetables will adapt to low radiation levels, and low temperatures and, consequently, quality is preserved even during failure of control system.

This study describes various designs of low energy buildings. It also, outline the effect of dense urban building nature on energy consumption, the problems related to inadequate ventilation in buildings, and its contribution to climate change. Measures, which would help to save energy in buildings, are also presented.

\section{Greenhouses Concept}

A greenhouse is essentially an enclosed structure, which traps the short wavelength solar radiation and stores the long wavelength thermal radiation to create a favourable microclimate for higher productivity. The sun's radiation incident on the greenhouse has two parts: direct radiation and an associated diffuse sky radiation. The diffuse part is not focused by the lenses and goes right through Frensel lenses onto the surface of the absorbers. This energy is absorbed and transformed into heat, which is then transported via the liquid medium in copper pipes to the water (heat) storage tanks or, if used, open fish tanks. In this way, an optimal temperature for both plant cultivation and fish production can be maintained. Stable plant growth conditions are light, temperature and air humidity. Light for the photosynthesis of plants comes from the diffuse radiation, which is without substantial fluctuations and variation throughout most of the day. The air temperature inside the greenhouse is one of the factors that have an influence on the precocity of production. The selective collector acts in a more perceptible way on extreme air temperatures inside the greenhouse. Hence, the system makes it possible to avoid the excessive deviation of the temperature inside the greenhouse and provides a favourable microclimate for the precocity of the culture. Sediment and some associated water from the sediment traps are used as organic fertiliser for the plant cultivation. The present trend in greenhouse cultivation is to extend the crop production season in order to maximise use of the equipment and increase annual productivity and profitability. However, in many Mediterranean greenhouses, such practices are limited because the improper cooling methods (mainly natural or forced ventilation) used do not provide the desired micro-climatic condition during the summer of a composite climate. Also, some of these greenhouses have been built where the meteorological conditions require some heating during the winter, particularly at night. The worst scenario is during the winter months when relatively large difference in temperature between day and night occurs. However, overheating of the greenhouse during the day is common, even in winter, requiring ventilation of the structure. Hence, several techniques have been proposed for the storage of the solar energy received by the greenhouse during the day and its use to heat the structure at night. Reviews of such techniques are presented in this chapter. Air or water can be used for heat transport. The circulating water is heated during the day via two processes. The water absorbs part of the infrared radiation of the solar spectrum. Since the water is transparent in the visible region, they do not compete with the plants that need it. Alternatively, the water exchanges heat with the greenhouse air through the walls. At night, if the greenhouse temperature goes down below a specified value, the water begins to circulate acting as heat transfer surfaces heating the air in the greenhouse. This chapter describes various designs of low energy greenhouses. It also, outlines the effect of dense urban building nature on energy consumption, and its contribution to climate change. Measures, which would help to save energy in greenhouses, are also presented. It also enabled the minimisation of temperature variation and, hence avoided the hazard of any sudden climatic change inside the greenhouse.

Population growth and less availability of food material have become global concerns. The world population increases exponentially whereas food production has increased only arithmetically, meaning that the availability of food per capita has decreased. This is more pronounced in the cases of oils, vegetables, fruits and milk, whereas it is marginal, rather than minimum, in cereals. The increase in population has also resulted in the use of more urban areas for habitation, less land available for cultivation and, hence, more food requirements. The resultant need is, therefore, to increase productivity and year round cultivation. To maximise production and meet the global demand on food, vegetables, flowers and horticultural crops, it is necessary to increase the effective production span of crops. The sun is the source of energy for plants and animals. This energy is converted into food (i.e., carbohydrates) by plants through a process called photosynthesis. This process is accomplished at suitable atmospheric conditions. These conditions are provided by nature in different seasons and artificially by a greenhouse. The primary objective of greenhouses is to produce agricultural products outside the cultivation season. They offer a suitable microclimate for plants and make possible growth and fruiting, where it is not possible in open fields. This is why a greenhouse is also known as a "controlled environment greenhouse". Through a controlled environment, greenhouse production is advanced and can be continued for longer duration, and finally, production is increased. ${ }^{4}$ The off-season production of flowers and vegetables is the unique feature of the controlled environment greenhouse. Hence, greenhouse technology has evolved to create the favourable environment, or maintaining the climate, in order to cultivate the desirable crop the year round. The use of "maintaining the climate" 
concept may be extended for crop drying, distillation, biogas plant heating and space conditioning. The use of greenhouses is widespread. During the last 10years, the amount of greenhouses has increased considerably to cover up to several hundred hectares at present. Most of the production is commercialised locally or exported. In India, about 300 ha of land are under greenhouse cultivation. On the higher side, however, it is 98600ha in Netherlands, 48000ha in China and 40000 ha in Japan. ${ }^{5}$ This shows that there is a large scope to extend greenhouse technology for various climates.

However, the effective utilisation of greenhouses has to deal with some specific climate problems like frost, during winter and overheating in summer days. These problems show the necessity of having a tool capable of predicting the thermal behaviour of a greenhouse under specific exterior conditions. Also, greenhouse industry has to deal with some problems related to a poor design of a great number of greenhouses. Such problems are mostly related to, on the one hand, its incapacity to deal with the problem of frost, which in the cold clear sky days of winter can destroy the whole work of a season, and, on the other hand, the question of overheating in the summer days.

\section{Greenhouses Environment}

The comfort in a greenhouse depends on many environmental parameters. These include temperature, relative humidity, air quality and lighting. Although greenhouse and conservatory originally both meant a place to house or conserve greens (variegated hollies, cirrus, myrtles and oleanders), a greenhouse today implies a place in which plants are raised while conservatory usually describes a glazed room where plants may or may not play a significant role. Indeed, a greenhouse can be used for so many different purposes. It is, therefore, difficult to decide how to group the information about the plants that can be grown inside it. Whereas heat loss in winter a problem, it can be a positive advantage when greenhouse temperatures soar considerably above outside temperatures in summer. Indoor relative humidity control is one of the most effective long-term mite control measures. There are many ways in which the internal relative humidity can be controlled including the use of appropriate ventilation, the reduction of internal moisture production and maintenance of adequate internal temperatures through the use of efficient heating and insulation.

The introduction of a reflecting wall at the back of a greenhouse considerably enhances the solar radiation that reaches the ground level at any particular time of the day. The energy yield of the greenhouse with any type of reflecting wall was also significantly increased. The increase in energy efficiency was obtained by calculating the ratio between the total energy received during the day in greenhouse with a reflecting wall, compared to that in a classical greenhouse. Hence, the energy balance was significantly shifted towards conservation of classical energy for heating or lighting. The four-fold greater amount of energy that can be captured by virtue of using a reflecting wall with an adjustable inclination and louvers during winter attracts special attention. When sky (diffuse) radiation that was received by the ground in amounts shown in Figure 1, were taken into account, the values of the enhancement coefficients were reduced to some extent: this was due to the fact that they added up to the direct radiation from the sun in both new and classical greenhouses. However, this is a useful effect as further increases overall energy gain. There is also an ironing out effect expressed in terms of the ratios between peak and average insulations.

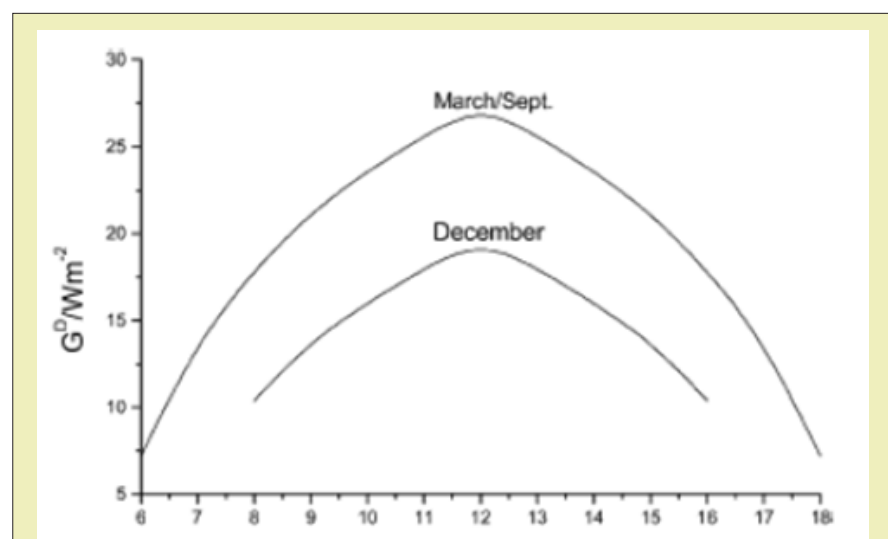

Figure 1: Ground irradiance from diffuse (sky) radiation from a clear sky at the shortest winter day and at equinox.

Finally, the presented theory can be used to calculate the expected effects of the reflecting wall at any particular latitude, under different weather conditions, and when the average numbers of clear days are taken into account. Thereby an assessment of the cost of a particular setup can be obtained. Under circumstances of a few clear days, it may still be worthwhile from a financial point of view to turn a classical greenhouse into one with a reflecting wall by simply covering the glass wall on the north-facing side with aluminium foil with virtually negligible expenditure.

\section{Relative Humidity}

Air humidity is measured as a percentage of water vapour in the air on a scale from $0 \%$ to $100 \%$, where $0 \%$ being dry and $100 \%$ being full saturation level. The main environmental control factor for dust mites is relative humidity. The followings are the practical methods of controlling measures available for reducing dust mite populations:

I. Chemical control.

II. Cleaning and vacuuming.

III. Use of electric blankets, and

IV. Indoor humidity.

\section{Solar Power}

Reflection of sunrays is mostly used for concentrating them onto reactors of solar power plants. Enhancing the insolation for other purposes has, so far, scarcely been used. Several years ago, application of this principle for increasing the ground irradiance in greenhouses, glass covered extensions in buildings, and for illuminating northward facing walls of buildings was proposed. Application of reflection of sun's rays was motivated by the fact that ground illuminance/irradiance from direct sunlight is of very low intensity in winter months, even when skies are clear, due to the low incident angle of incoming radiation during most of the day. This is even 
more pronounced at greater latitudes. As can be seen in Figure 2, which depicts a sunbeam split into its vertical and horizontal components, nearly all of the radiation passes through a greenhouse during most of the day.

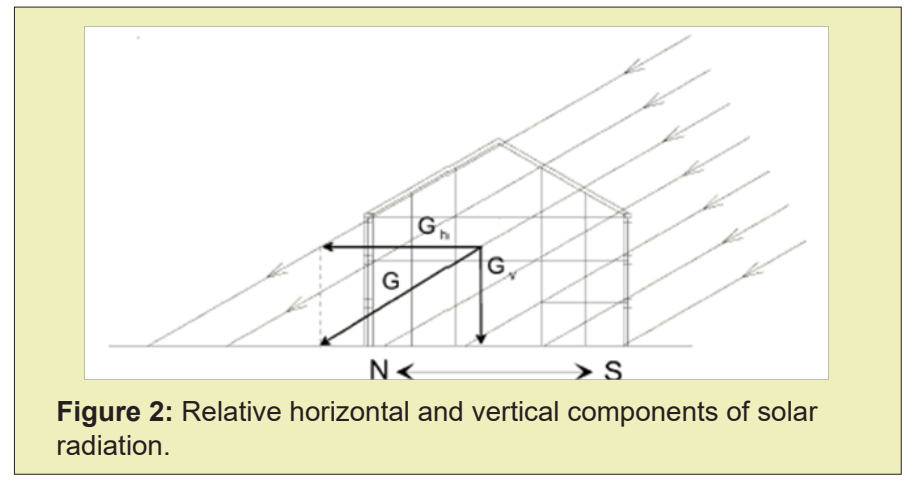

The possibility of capturing the horizontal component of sun's rays that merely passes through a greenhouse, and of reflecting it to the ground was explored. Different ways of diverting most of the radiation and using it inside the greenhouse throughout an entire day were examined. Four different types of greenhouses, in orders of increasing sophistication were investigated (Figure 3). These are:

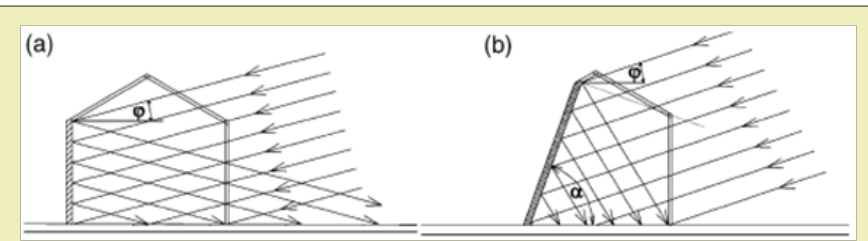

Figure 3: Greenhouse types according to the applied mode of reflection of solar radiation: (a) fixed vertical reflecting wall (b) fixed inclined reflecting wall (c) reflecting wall with variable inclination (d) reflecting wall with louvers.

I. A classical greenhouse, in which a vertical section of its northern wall was covered by a reflecting material (e.g., aluminium foil, and metalisation spraying of existing glass).

II. A specially constructed greenhouse with its northern wall inclined at an optimum angle and covered with a reflecting material intended for directing sunlight towards the ground.

III. A classical greenhouse with a reflecting panel placed on the northern wall whose inclination could be changed by a special mechanism in order to provide maximal returns with changing incident angles of the sun throughout the day.

IV. A greenhouse with a reflecting wall divided into vertical sections (louvers), which could rotate on a vertical axis so as to provide maximal returns with changing azimuths of sun's angles.

The quality of life practiced by people is usually represented as being proportional to the per capita energy use of that particular country. It is not surprising that people want to improve their quality of life. Consequently, it is expected that the demand for commercial energy resources will increase at a greater rate in the years to come.

Each type of greenhouse could achieve significant increases of ground insolation. It should be larger the sun is, and from dawn to dusk enhancements of ground illuminance and/or irradiance should be higher the lower the maximal incident angle is for a particular day. Conversely, the reflecting wall obstructs a part of the diffuse radiation, increasingly lowering its contribution to the overall irradiance; the more inclined the wall is.

\section{The effect of diffuse radiation}

A contribution to the ground radiation in a classical greenhouse arises from diffuse light from the entire sky hemisphere. This amounts to an integral of diffuse radiation arriving from all incident angles of elevation, from $0^{\circ}$ to $180^{\circ}$, and of azimuths ranging from $0^{\circ}$ to $360^{\circ}$. Two cases of diffuse radiation are presently analysed: isotropic (from an evenly cloudy sky), and anisotropic (from a clear sky). The implication from the two extremes is that a real situation would most of the time lie somewhere in between. The presence of a reflecting wall reduces access of diffuse radiation to the ground, as shown schematically in Figure 4. Thus, it is obvious that direct contribution of diffuse radiation to ground radiation in a greenhouse with a reflecting wall is smaller than in a classical greenhouse by the shadow of the reflecting wall. However, the reflecting wall also reflects some of the diffuse radiation arriving from the part of the sky not obstructed by the wall. To control the energy used for the cooling of buildings in hot-arid regions with ambient air temperatures during the hottest period between 42 to $47^{\circ} \mathrm{C}$, passive cooling approaches should be implemented. A solar chimney that employs convective currents to draw air out of the building could be used. By creating a hot zone with an exterior outlet, air can be drawn into the house, ventilating the structure as well as the occupants. This shows that there is a large scope to extend greenhouse technology for various climates.

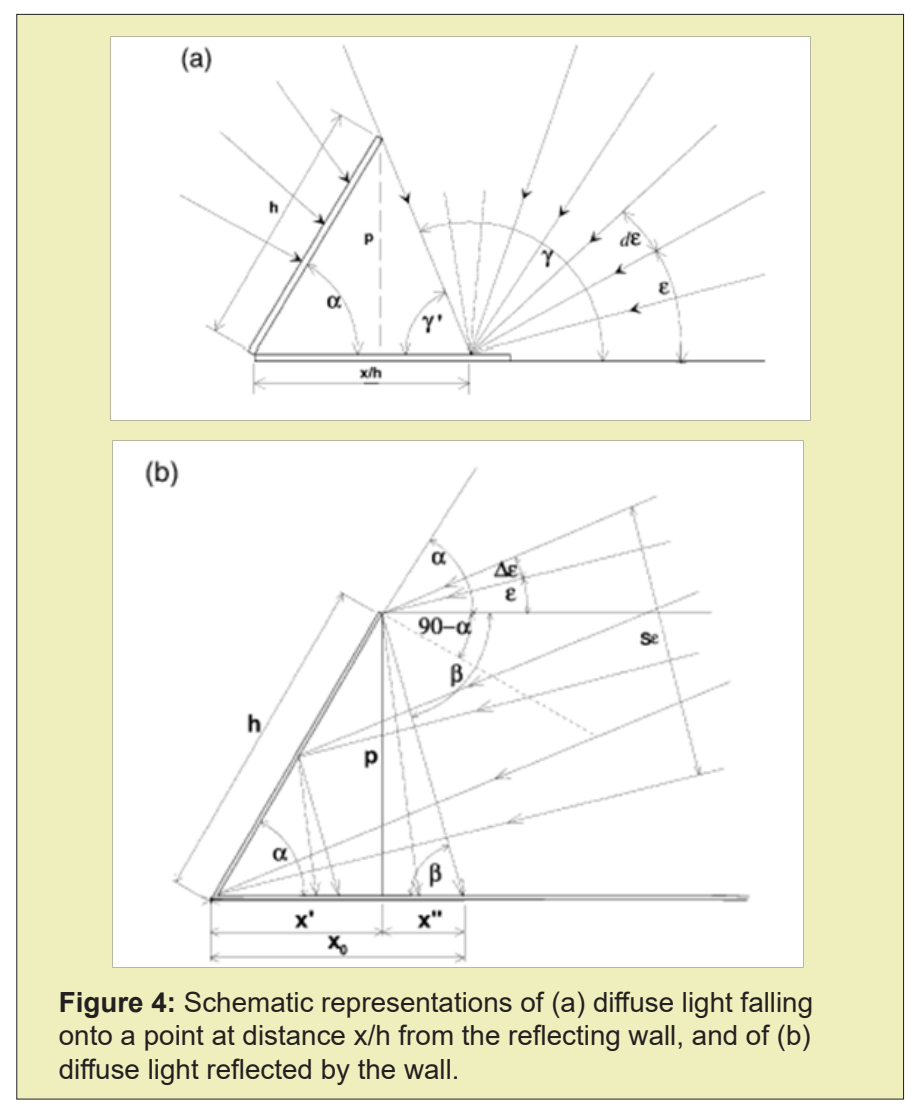


The introduction of a reflecting wall at the back of a greenhouse considerably enhances the solar radiation that reaches the ground level at any particular time of the day. The energy yield of the greenhouse with any type of reflecting wall was also significantly increased. The increase in energy efficiency was obtained by calculating the ratio between the total energy received during the day in greenhouse with a reflecting wall, compared to that in a classical greenhouse. Hence, the energy balance was significantly shifted towards conservation of classical energy for heating or lighting. The four-fold greater amount of energy that can be captured by virtue of using a reflecting wall with an adjustable inclination and louvers during winter attracts special attention. When sky (diffuse) radiation that was received by the ground in amounts shown in Figure 1, were taken into account, the values of the enhancement coefficients were reduced to some extent: this was due to the fact that they added up to the direct radiation from the sun in both new and classical greenhouses. However, this is a useful effect as further increases overall energy gain. There is also an ironing out effect expressed in terms of the ratios between peak and average insulations.

Finally, the presented theory can be used to calculate the expected effects of the reflecting wall at any particular latitude, under different weather conditions, and when the average numbers of clear days are taken into account. There by an assessment of the cost of a particular setup can be obtained. Under circumstances of a few clear days, it may still be worthwhile from a financial point of view to turn a classical greenhouse into one with a reflecting wall by simply covering the glass wall on the north-facing side with aluminium foil with virtually negligible expenditure.

Many cities around the world are facing the problem of increasing urban density and energy demand. As cities represent a significant source of growth in global energy demand, their energy use, associated environmental impacts, and demand for transport services create great pressure to global energy resources. Low energy design of urban environment and buildings in densely populated areas requires consideration of a wide range of factors, including urban setting, transport planning, energy system design, and architectural and engineering details. It is found that densification of towns could have both positive and negative effects on the total energy demand. With suitable urban and building design details, population should and could be accommodated with minimum worsening of the environmental quality.

\section{Discussion}

A novel mop fan has been implemented for studying the thermal behaviour in the greenhouse after evaporative cooling (fan) using a liquid desiccant potassium format introduced at the inlet of a flexible fibre impeller. A novel air humidifier and/or dehumidifier systems using mop fans (indoor temperature and humidity) has been employed to enhance the performance of the system, hence, reducing energy consumption, decreasing load in the greenhouse, and reducing manufacturing cost. The system has been designed taking into account the meteorological conditions to control the environment inside the greenhouse. To supervise the growing of plants, outdoor and indoor temperatures, and relative humidity were measured. The indoor temperature measurements were made at the top and bottom of the greenhouse (in the middle and near the door). The system has allowed providing temperatures inside the experimental greenhouse favourable to most greenhouse plants (the comfort level for active healthy growth is $16-26^{\circ} \mathrm{C}$ ). In the experimental greenhouse, the system has allowed a relative humidity range between $30 \%-65 \%$, which is favourable to the plants. It, also, enabled the reduction of the difference between minimum and maximum temperatures so as to avoid sudden climatic variations. Recent advances in thin film coatings for greenhouse glass products provide a means of substantially reducing heat gain without proportionally reducing daylight transmittance. It means that the energy expenditures due to lighting can be minimised, while plants can enjoy more natural light and maintain visual contact with the outside environment. In recent years, research activities in the field of using desiccant-based air conditioning systems are finding applications in humidity control devices. With some modifications, these systems may be used for recovering water from ambient air in arid areas. Desiccant-based water recovery from atmospheric air systems has great potential for use in solar energy applications. The system involves night absorption of water vapour from ambient air and simultaneous desiccant regeneration and water vapour condensation during the daytime. The results of the experimental tests are encouraging, further research and development is necessary to get commercially interesting products. It is, also, interesting to develop further studies about the utilisation of additional coatings that could reduce the heat loss in winter and limit the heat penetration in summer.

\section{Conclusion}

Thermal comfort is an important aspect of human life. Buildings where people work require more light than buildings where people live. In buildings where people live the energy is used for maintaining both the temperature and lighting. Hence, natural ventilation is rapidly becoming a significant part in the design strategy for non-domestic buildings because of its potential to reduce the environmental impact of building operation, due to lower energy demand for cooling. A traditional, naturally ventilated building can readily provide a high ventilation rate. On the other hand, the mechanical ventilation systems are very expensive. However, a comprehensive ecological concept can be developed to achieve a reduction of electrical and heating energy consumption, optimise natural air condition and ventilation, improve the use of daylight and choose environmentally adequate building materials. Plants, like human beings, need tender loving care in the form of optimum settings of light, sunshine, nourishment, and water. Hence, the control of sunlight, air humidity and temperatures in greenhouses are the key to successful greenhouse gardening. The mop fan is a simple and novel air humidifier; which is capable of removing particulate and gaseous pollutants while providing ventilation. It is a device ideally suited to greenhouse applications, which require robustness, low cost, minimum maintenance and high efficiency. A device meeting these requirements is not yet available to the 
farming community. Hence, implementing mop fans aids sustainable development through using a clean, environmentally friendly device that decreases load in the greenhouse and reduces energy consumption.(Appendix)

\section{Acknowledgments}

None.

\section{Funding}

None.

\section{Conflicts of Interest}

Author declares that there is no conflicto of interest.

\section{References}

1. Jeremy L. The energy crisis, global warming and the role of renewables. Renewable Energy World. 2005;8(2).

2. Omer A. Low energy building materials: an overview. In: Proceedings of the Environment 2010: Situation and Perspectives for the European Union. Porto: Portugal. 2003:16-21.

3. UNEP. Handbook for the International Treaties for the Protection of the Ozone Layer. United Nations Environment Programme. Nairobi: Kenya. 2003.

4. Viktor D. Ventilation concepts for sustainable buildings. In: Proceedings of the World Renewable Energy Congress VII. Cologne: Germany. $2002 ; 551$.

5. Lam JC. Shading effects due to nearby buildings and energy implications. Energy Conservation and Management. 2000;47(7):647-659. 